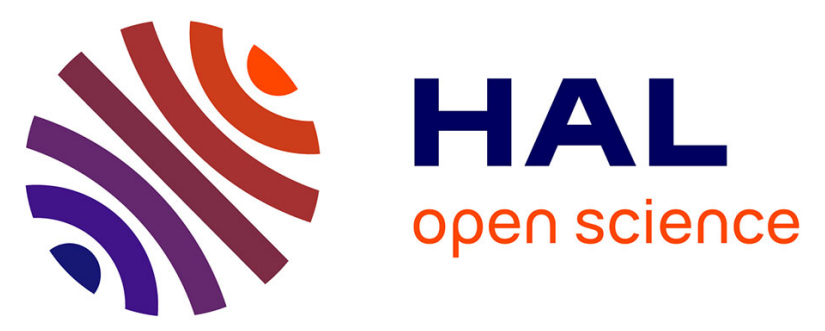

\title{
Systems Engineering Approach for eco-comparison among power-train configurations of hybrid bus
}

El-Mehdi Azzouzi, Mariangela Iuliano, Felipe Camargo Rosa, Moncef Hammadi, Stanislao Patalano, Ottorino Veneri, Clemente Capasso

\section{To cite this version:}

El-Mehdi Azzouzi, Mariangela Iuliano, Felipe Camargo Rosa, Moncef Hammadi, Stanislao Patalano, et al.. Systems Engineering Approach for eco-comparison among power-train configurations of hybrid bus. IEEE Systems Conference (SysCon), Apr 2016, Orlando, Florida, United States. 10.1109/SYSCON.2016.7490570 . hal-01337356

\section{HAL Id: hal-01337356 https://hal.science/hal-01337356}

Submitted on 25 Jun 2016

HAL is a multi-disciplinary open access archive for the deposit and dissemination of scientific research documents, whether they are published or not. The documents may come from teaching and research institutions in France or abroad, or from public or private research centers.
L'archive ouverte pluridisciplinaire HAL, est destinée au dépôt et à la diffusion de documents scientifiques de niveau recherche, publiés ou non, émanant des établissements d'enseignement et de recherche français ou étrangers, des laboratoires publics ou privés. 


\section{Systems Engineering Approach for eco-comparison among power-train configurations of hybrid bus}

\author{
El-Mehdi AZZOUZI \\ Mariangela IULIANO \\ Felipe CAMARGO-ROSA \\ Institut Supérieur de Mécanique de Paris \\ Saint-Ouen, France \\ el-mehdi.azzouzi@edu.supmeca.fr \\ mariangela.iuliano@edu.supmeca.fr \\ felipecamargo36@gmail.com \\ Stanislao PATALANO \\ University of Naples Federico II \\ Department of Industrial Engineering, \\ P.le V. Tecchio 80, 80125 Naples (Italy) \\ patalano@unina.it
}

\author{
Moncef HAMMADI \\ Quartz EA 7393 \\ Institut Supérieur de Mécanique de Paris \\ Saint-Ouen, France \\ moncef.hammadi@supmeca.fr \\ Ottorino VENERI \\ Clemente CAPASSO \\ Istituto Motori \\ CNR National Research Council of Italy, \\ Via Marconi 4, 80125 Naples (Italy) \\ o.veneri@im.cnr.it
}

\begin{abstract}
This paper aims to realize an eco-comparison among power-train configurations of hybrid busses in terms of performance, fuel consumption and $\mathrm{CO} 2$ emission. The present study has been carried out in the context of the international research program PLACIS (PLAteforme Collaborative d'Ingénierie Systèmes). In this work, experimental data of a pure electric power-train, evaluated in a dedicated laboratory of Istituto Motori - the National Research Council of Italy, have been used to carry out a pre-design phase of the modelling procedure. From that point on, in order to optimize the powertrain performance, a series hybrid vehicles configuration and a parallel one have been modeled and simulated on DYMOLA-MODELICA environment. The vehicle that has been taken into account, as reference for the comparison, is a "RENAULT-Master" minibus. Power-trains have been modeled with a backward-forward configuration in order to have a physical approach to the problem, respecting the required performances. The study has been developed with System Engineering approach that aims to manage the complexity of systems with a multidisciplinary proposal.
\end{abstract}

Keywords-Eco-comparison; Dymola; Modelica; Electrical power-train; Backward-forward configuration; Hybrid Electric Vehicles; System Engineering; PLACIS; $\mathrm{CO}_{2}$ emission;

\section{INTRODUCTION}

Nowadays society is continually seeking to provide a greater and easier mobility in everyday life. However, it has to take into consideration transport pollution problems such as global warming and the destruction of ozone layer [1].

In the other hand we become more and more aware of the importance of the smart use of the resources given their nonrenewable nature.

As a result of these environmental and energy issues, research started to focus on a new generation of clean vehicles that use electric energy [2].
Electric vehicles (EV) face a slow development because of the high battery cost, the limited driving range and performance. Thereby, recently, research concentrates on the development of Hybrid Electric Vehicles (HEVs).

HEVs keep Internal Combustion Engine (ICE) and EVs advantages and minimize their disadvantages. They achieve to get a greater fuel economy and a lower $\mathrm{CO}_{2}$ emission than conventional ICE vehicles. These benefits stem from these characteristics:

- Smaller ICE sized, that leads to less internal losses and lower weight.

- $\quad$ Significant battery storage capacity to store energy and reuse it especially in stop-and-go traffic which is typical of the city driving cycle.

- Regenerative braking that converts kinetic energy into electricity [4].

There are several configurations of Hybrid vehicles. In this study we carried out an eco-comparison between series and parallel configurations. Our goal was to accomplish a performance's analysis, in terms of the battery's autonomy, the total range and the driving time. We also conducted an ecological analysis in terms of fuel consumption and $\mathrm{CO}_{2}$ emission in order to respect the new European standards "COM (2009) 593 of 28/10/2009" [12]. To deal with complex systems, such as hybrid power train vehicles, System Engineering approach has been used. Thus, our work consisted in analyzing experimental data of electric buses, modelling and simulating two hybrid power train configurations with better performances and then realize an eco-comparison between them. 


\section{HYBRID CONFIGURATIONS:STATE OF ART}

\section{A. Series Hybrid configuartion (SHVs)}

The "Fig. 1" shows one of the common series hybrid electric drive train. In this case, we have a single power plant, the electric motor that propels the vehicle and two power sources: the fuel tank and the battery. ICE can work to charge the battery or to provide energy to the electric motor, according to the operation mode chosen in the modeling.

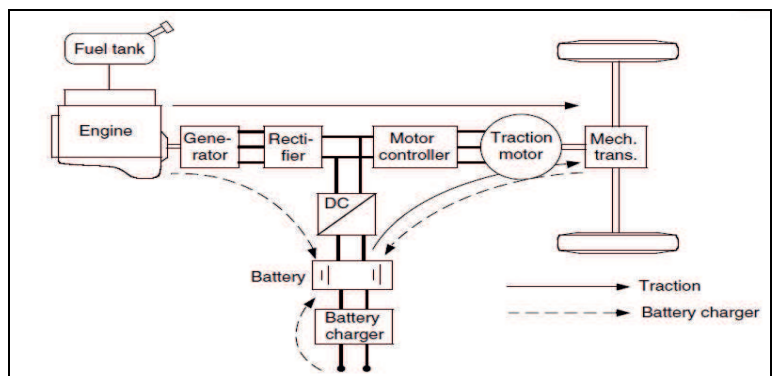

Fig. 1. Configuration of a series hybrid electric drive train [4]

\section{B. Parallel Hybrid configuration (PHVs)}

In the parallel configuration, "Fig. 2", ICE and electric motor can both of them supply energy to the wheels. They can work separately or together.

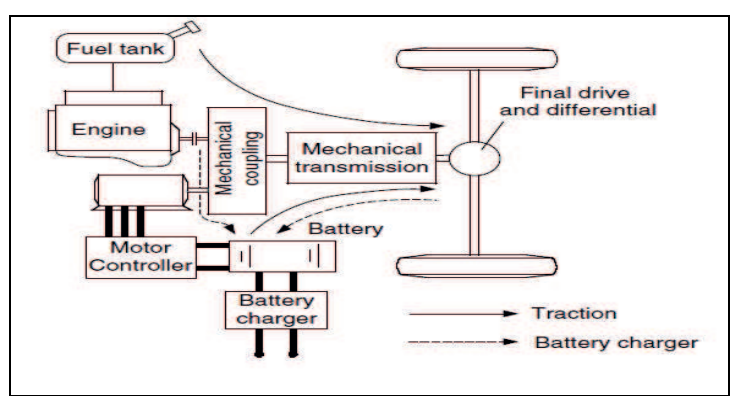

Fig. 2. Configuration of a parallel hybrid electric drive train [4]

The major advantages of the parallel configuration over a series configuration are that the generator is not required, the traction motor is smaller and the Multi-conversion of the power from the engine to the driven wheels is not necessary [7]. Hence, the overall efficiency can be higher. However, the control of the parallel hybrid drive train is more complex than a series hybrid drive train, due to the mechanical coupling between the engine and the driven wheels.

\section{PROJECT CONTEXT AND OBJECTIVE}

The present work was carried out in the context of the international research program PLACIS (in French, "Plateforme Collaborative d'Ingénierie Systèmes").

This program allowed to carry out the study described in the present paper through a partnership between the engineering school SUPMECA - Institut Supérieur de Mécanique de Paris, the University of Naples Federico II and CNR - National Research Council of Italy - Istituto Motori.
The collaborative platform of PLACIS permitted to deal with problems of designing, testing and evaluating engineering systems, facilitating the coordination between different teams, established in different countries. This program is integrated in the context of System Engineering because it aims to manage complex engineering systems with a multidisciplinary approach [3].

System engineering is a robust approach to the design, the creation, and the operation of systems. In easier words, the approach consists of the identification and quantification of system goals, the creation of alternative system design concepts, performance of design trades, selection and implementation of the best design, the verification that the design is properly built and integrated, and postimplementation assessment of how well the system satisfies the need [5].

It focuses on defining customers' needs and required functionality in an early stage of the development cycle and documenting requirements before proceeding with the design and system validation, with an iterative process of top-down synthesis [6].

This path has been followed during all the stages of the work. We identified the goal of our project, i.e. to design and model a hybrid powertrain, and then we proposed two alternative configurations to improve the performances of the pure electrical power-train. We carried out a multidisciplinary analysis, in terms of ecological, economics and mechanical performances. We aim to validate the results by doing experimental tests in laboratory. In the following part, different modelling and simulation approaches used in powertrain design, are discussed. The choice to consider a backwardforward approach is argued.

\section{FORWARD-BACKWARD APPROACH}

\section{A. Backward facing approach}

This approach assumes that the vehicle's speed already meets the required driving cycle, then we analyze the behavior of the rest of the subsystems. This approach makes the computation of the efficiency of the components simple, and enables a fast progress of calculation.

On the other hand, this approach doesn't take into consideration the dynamic effects that are not integrated on the maps of efficiency or losses, due to the fact that they are tested on a steady state [8].

\section{B. Forward-Facing Approach}

This approach takes into account a real driver's cycle that considers the actual speed of the vehicle and the required one. Based on that, the model can choose the right throttle to make them meet. This will be converted into a torque that will be sent to the transmission system. It is convenient because it deals with a physical drivetrain and not what is required from the elements.

But on the other hand, this approach takes a longer simulation time than the one above. Indeed, it requires multiple time steps to have stable and reliable results [9]. 


\section{DYMOLA POWER-TRAIN MODEL}

Our model is based on a Backward-Forward approach that will no longer require more power or torque that it can provide. Components will be efficient enough to make a fast and reliable simulation [8].

The model was realized in Dymola environment and aims to evaluate the Renault-Master minibus's performance.

The model is composed of both original blocks contained in Modelica library and new ones that were developed based on the fundamental equations that control the behavior of each electrical or mechanical part of the system.

\section{A. Dymola Series Hybrid Electric Vehicle (SHEV) Model}

Following SE approach, we divided our system into subsystems to make the analysis easier. Thereby, the model contains eight main parts as shown on the "Fig. 3".

Driving cycle, Control System, Electric Drive, Generator, Battery Pack, Internal Combustion Engine, Transmission system, Resistive Forces.

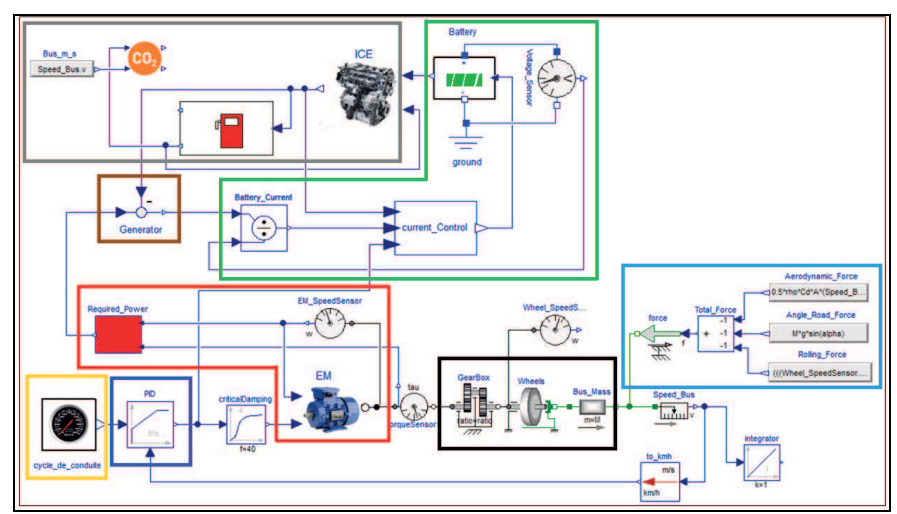

Fig. 3. Series Hybrid Electric Model

\section{1) Driving cycle}

When dealing with vehicle's propulsion system modelling, it's important to choose the correct driving cycle that fits your problem. In the current case, we chose the Urban Driving cycle ECE15 based on the usual driving conditions of heavy vehicles when running in an urban area. Moreover, this cycle has been designed to represent typical driving conditions of crowded European cities. It is characterized by low engine load, low exhaust gas temperature and a maximum speed of $50 \mathrm{~km} / \mathrm{h}$, which is very adequate to the current problem.

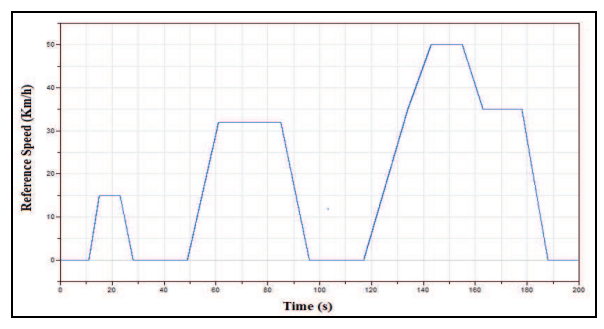

Fig. 4. Driving Cycle ECE15

\section{2) Electrical components}

The electrical configuration of the hybrid propulsion system is composed of: a battery pack, an inverter, an electric motor and a generator (which is typically used on SHEV systems). However, in the current model, these components were modelled using simple methods that could simulate the behavior of each component without taking into account the particularities of their electrical functioning.

\section{a) Battery Pack}

Modelling the battery is generally a complex task since all the main parameters (Voltage, Current, Temperature and State Of Charge) are interconnected to each other in a non-linear way.

In this part, our aim was to create a model that simulates the behavior of the battery used in the real case of a hybrid bus. The model developed should consider the discharging and charging effects present in specific moments during the simulation. It has a cyclical behavior where each state of the battery takes into account the previous one.

To compute the SOC (State Of Charge), we defined as inputs, the battery capacity and the current $\mathrm{i}(\mathrm{t})$. The battery uses the following equation to compute its instantaneous state of charge:

$$
\operatorname{SOC}(\mathrm{t})=-\frac{1}{c} \int_{T 0}^{T} i(t) d t
$$

This instant value is inserted as an input on a table which represents the dependence of the behavior between the SOC and the battery cell voltage [11].

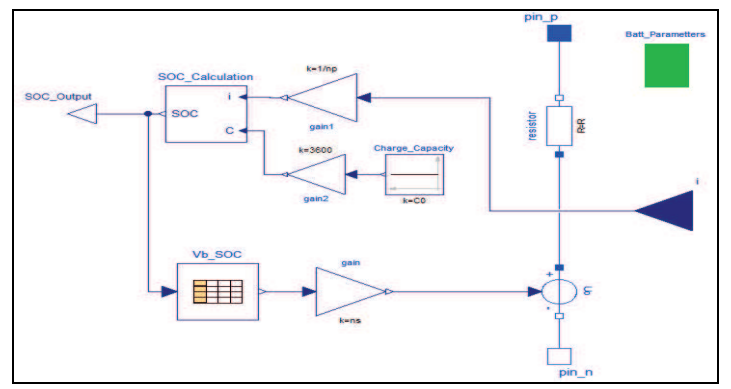

Fig. 5. Battery pack's Dymola model

\section{b) Electrical Motor}

The model of the Electric Motor (EM) is based on experimental data which correlate speed rotation to applied torque.

Thereby, this data were converted into a table and inserted on the Dymola model. The inputs of this component are the motor shaft's speed rotation, measured by an angular velocity sensor and the throttle imposed by the control system in order to approximate the actual speed of the vehicle to the reference speed of the driving cycle. We also integrated a component "EM_inertia" to make sure the model suits the reality. 


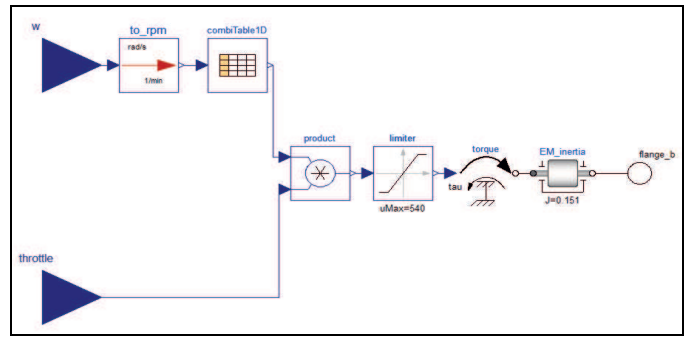

Fig. 6. Electric Motor's Dymola model

\section{c) Power Losses Computation}

This part represents the transition between the Forward and Backward modelling parts described above. It includes the losses due to both, electrical motor and inverter.

The efficiency of the EM is computed based on a reference table that takes into consideration the two input signals of the model, the EM's speed rotation and torque.

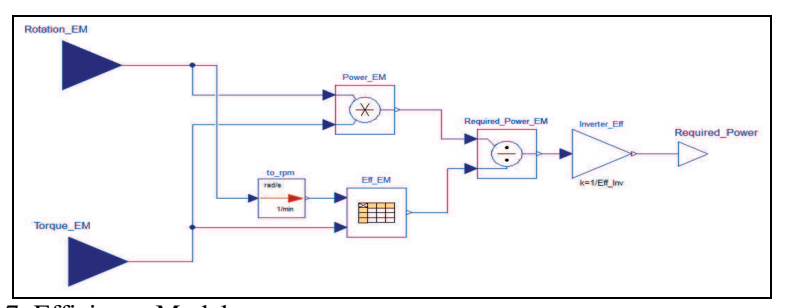

Fig. 7. Efficiency Model

The value of the useful power of the EM is divided by its efficiency and then by the inverter efficiency. In this way, the final required power is obtained.

\section{d) Internal Combustion Engine (ICE)}

In the series model, the ICE works with a nominal power. It only works to charge the battery or to supply energy to the electric motor. It's totally independent from the traction transmission and the required speed.

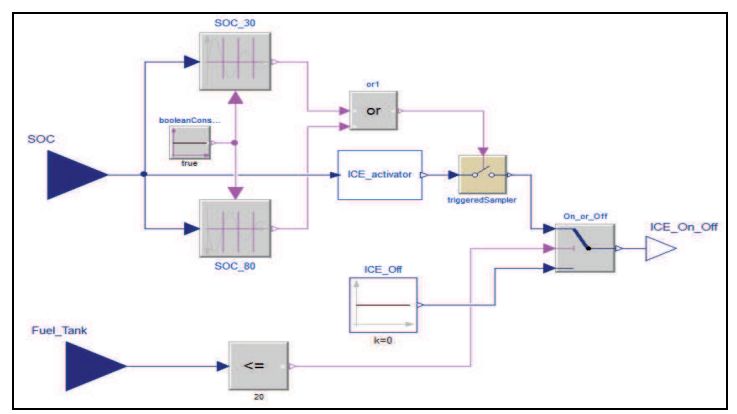

Fig. 8. Series Hybrid Electric Motor's Internal Combustion Model

Inputs component are the battery's State Of Charge and the level of fuel tank. This one is limited by a maximum capacity of 20 liters.

ICE works between two limits of SOC: a superior limit at $80 \%$ and an inferior limit at $30 \%$. If SOC $>80 \%$ ICE turns off.

This strategy is assumed in order to preserve and optimize the battery's lifetime.

\section{e) Fuel Consumption and efficiency}

In this part, we computed the efficiency of the ICE and the fuel consumption based on a Boolean switch component to model when the ICE is on or off and a table that reports specific consumption values.

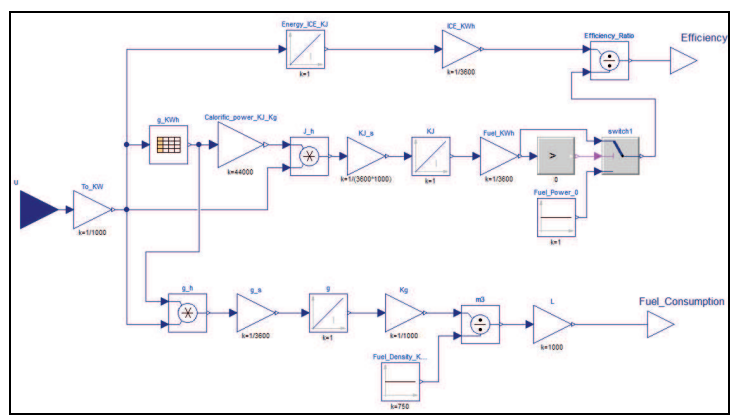

Fig. 9. Fuel consumption model

f) $\mathrm{CO}_{2}$ Emission's Computation

To calculate the $\mathrm{CO}_{2}$ emission, this component takes into account the consumption of the fuel and also the bus's speed, which allows us to estimate the emission per $\mathrm{km}$.

The emission is computed by using stoichiometric coefficients of Diesel based on (2):

$$
4 \mathrm{C}_{12} \mathrm{H}_{23}+71 \mathrm{O}_{2} \rightarrow 48 \mathrm{CO}_{2}+46 \mathrm{H}_{2} \mathrm{O}
$$

This part was made with a Modelica script.

\section{g) Transmission System}

The transmission between the electric motor and the wheels of the bus is insured by a gear box with a ratio of 6 . The rotational speed of the wheels is then transformed into a linear speed that is related to the mass of the bus.

\section{h) Resistive Forces}

In the case of the resistive forces, we took into consideration the aerodynamic force, the force due to the road slope and the rolling force.

\section{i) Control System}

The SHEV model is controlled with one PID that is linked to the driving cycle, the electric motor and also the bus speed.

\section{B. Dymola Parallel Hybrid Electric Vehicle (PHEV) Model}

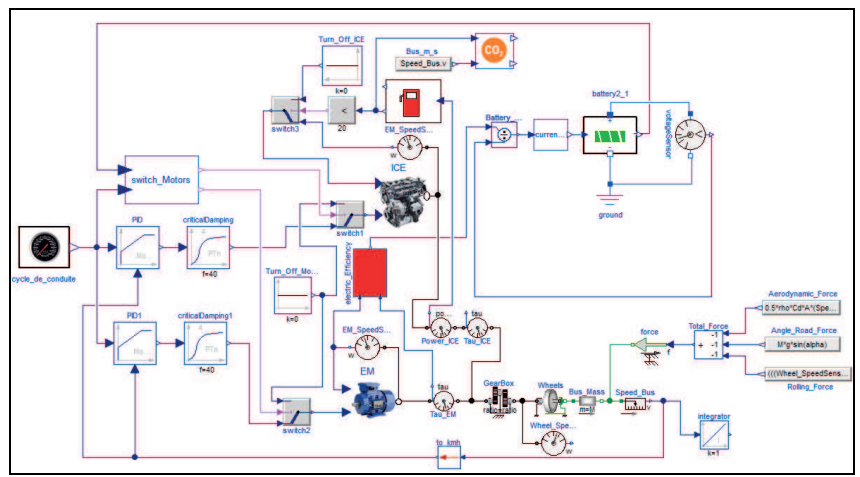

Fig. 10. Parallel Hybrid Electrical Vehicle's Model 


\section{a) ICE Model}

The model of the Internal Combustion Engine (ICE) is based on experimental data which correlate speed rotation to the applied torque. This data were integrated on a table and inserted in Dymola model.

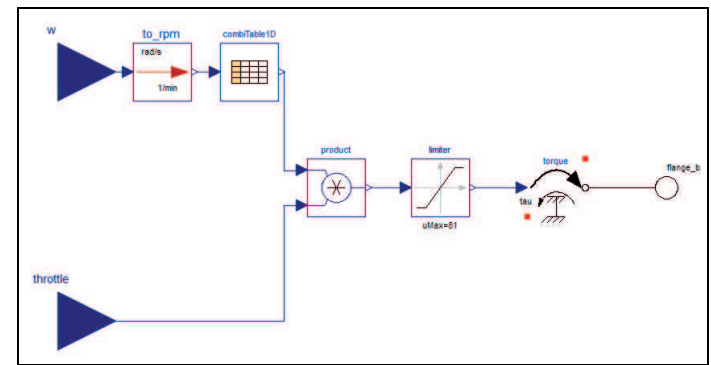

Fig. 11. Internal Combustion Model of the Series Hybrid configuration

\section{b) Parallel Switch Control System}

The purpose of this system is to settle commutation between the ICE and electric motor of the minibus according to the driving conditions that the vehicle faces while running.

The developed model for this system takes into account the SOC of the battery and the minibus speed.

The strategy of switching between the electric motor and the internal combustion engine is especially based on the speed of the minibus. Indeed, the strategy adopted is as following:

- $0<\mathrm{V}<22 \mathrm{~km} / \mathrm{h}$ (EM is turned on and ICE is turned off)

- $22 \mathrm{~km} / \mathrm{h}<\mathrm{V}<36 \mathrm{~km} / \mathrm{h}$ (ICE is turned on and EM is turned off)

- $\mathrm{V}>36 \mathrm{~km} / \mathrm{h}$ (both ICE and EM are turned on)

We chose to use the EM at low speed due to his good performances in this range, in opposite, ICE works better at high speed.

\section{RESULTS:}

\section{A. Vehicle Speed}

"Fig. 12" shows the response of both models. The SHEV follows better the driving cycle than the PHEV.

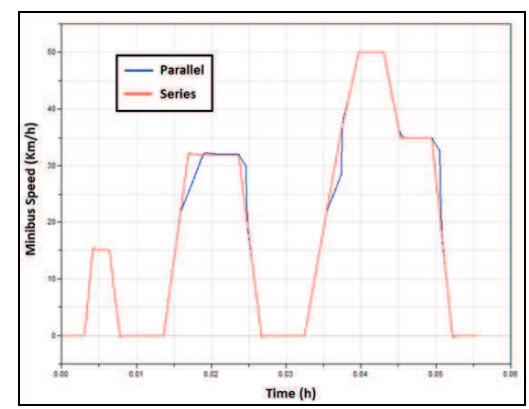

Fig. 12. Vehicle speed of SHEV and PHEV

The difference is due to the fact that beyond $22 \mathrm{~km} / \mathrm{h}$, the electric motor turns off and the ICE turns on. The problem is that the ICE cannot afford enough couple to give the required throttle and speed. To fix this problem, a more powerful ICE should be used.

\section{B. SOC in one driving cycle}

As we can see in "Fig. 13", the SOC of battery decreases faster in the SHEV. Indeed, in the series model, the electric motor works alone until discharging. On the other hand, in the parallel model, the electric motor just work from 0 to $22 \mathrm{~km} / \mathrm{h}$ and beyond $36 \mathrm{~km} / \mathrm{h}$.

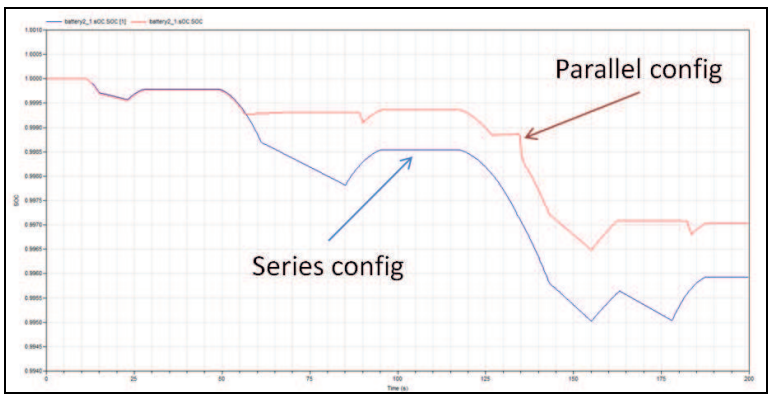

Fig. 13. Battery SOC in one driving cycle

\section{SOC/Autonomy}

The behavior of the battery is totally different between the two configurations. Indeed, in the PHEV, the battery only gets discharged once, instead of multiple times for the SHEV, as we can see on the "Fig.14".

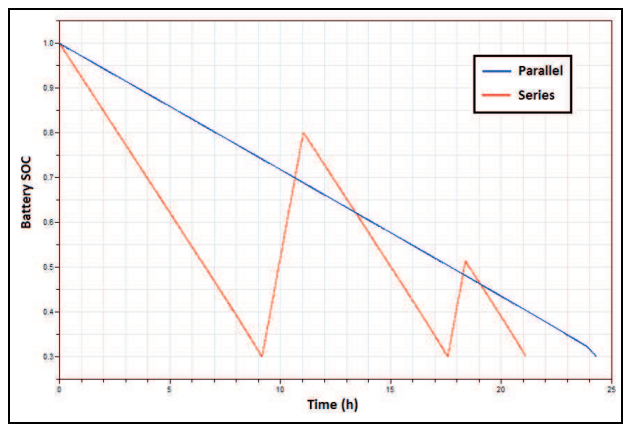

Fig. 14. SOC of parallel and series model

In both simulations (parallel and series) we used a fuel tank of 20 liters, but we got a considerable difference of the autonomy. Indeed, the driving time of the parallel model is 3.5 hours longer than the series one.

Moreover, the fact of getting discharged one time rather than three in the same period makes the life time of the battery longer in the PHEV configuration.

\section{D. $\mathrm{CO}_{2}$ emission}

The $\mathrm{CO}_{2}$ emission differs from a model to another, that's because the ICE works at every driving cycle for the PHEV, while it only works to charge the battery for the SHEV.

"Fig. 15" shows that the average $\mathrm{CO}_{2}$ consumption is $105 \mathrm{~g} / \mathrm{km}$ for the PHEV and $120 \mathrm{~g} / \mathrm{km}$ for the SHEV. 


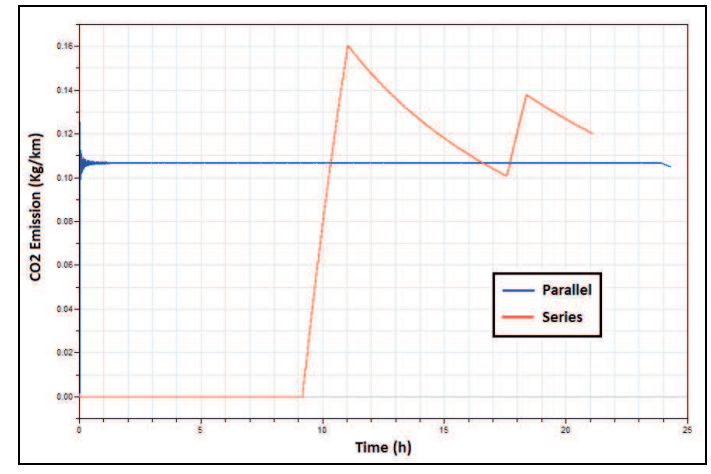

Fig. 15. $\mathrm{CO}_{2}$ emission of Series and Parallel configurations

Both results respect the European standards regarding the light-duty hybrid vehicles CO2 emission. "COM (2009) 593 of 28/10/2009" establishes that light-duty hybrid vehicles CO2 emission should be less than $175 \mathrm{~g} / \mathrm{km}$ within 2016 and less than $135 \mathrm{~g} / \mathrm{km}$ within 2020 [12].

\section{E. Results:}

TABLE I. RESULTS OF SIMULATION OF SHEV, PHEV MODELS AND EV EXPERIMENTAL DATA, FOR 0\% SLOPE

\begin{tabular}{|l|c|c|c|}
\hline \multicolumn{1}{|c|}{ Criteria of comparison } & SHEV & PHEV & $\boldsymbol{E V}$ \\
\hline Total Range(km) & 381,9 & 451 & 113,5 \\
\hline Driving Time (h) & 20,8 & 24,3 & 6,19 \\
\hline Discharge Time (h) & 8,9 & 24,3 & 6,19 \\
\hline Initial SOC (\%) & 100 & 100 & 100 \\
\hline Final SOC (\%) & 30 & 30 & 30 \\
\hline Average $\mathrm{CO}_{2}$ Emission (g/km) & 120 & 105 & 0 \\
\hline Fuel Tank (1) & 20 & 20 & 0 \\
\hline
\end{tabular}

\section{CONCLUSIONS}

Modelling a power-train of a hybrid bus is a complex task that needs to be divided into several stages and be managed through an approach typical of Systems Engineering.

Pure electric vehicles performance are limited compared to the Hybrid configurations as evaluated in this paper.

On the other hand, the PHEV model gives much more advantages than the series one. Indeed, the range of the PHEV is $70 \mathrm{~km}$ longer. It also has an average of $\mathrm{CO} 2$ emission that is considerably smaller than the SHEV. Moreover, In the PHEV, the battery may have a longer life time, because it only gets discharged once, instead of 2 or 3 times for the SHEV, for the same driving cycle.

However, we should take into account the fact that the component that would be used for a PHEV might be more complex and more expensive. Actually, in the PHEV, it's essential to have a gear-box to combine the torques coming from the electric motor and the ICE. Moreover, in the PHEV, we need a more powerful ICE since the one that we used couldn't afford the required power. On the other hand, the SHEV requires a generator between the battery and the ICE.

Considering the performing results regarding hybrid configuration obtained in a pre-design phase, we can conclude that the experimentation phase could be launched to validate them, according to System Engineering approach.

\section{ACKNOWLEDGMENT}

We would like to acknowledge funding support from PLACIS Project, ANR-11-IDFI-0029. Our thanks to Mr.Antoine Brunner, Mr.Antoine Lanthony and Ms.Yimeng Dong for their support and coordination during all the period of our project. We also thank our Italian colleague Eng. Giovanni Copertino for his contribution to simulations and Mr.Antonio Rossi for his technical support in laboratory.

\section{REFERENCES}

[1] Chu, Steven, and Arun Majumdar. "Opportunities and challenges for a sustainable energy future" nature 488.7411 (2012): 294-303.

[2] A. G. Boulanger, A. C. Chu, S. Maxx and D. L. Waltz, "Vehicle electrification: status and issues" Proceedings of the IEEE, vol. 99, 0177 SIP 2010 PIEEE.R1.

[3] M. Hammadi, J.-Y. Choley, O. Pen and A. Riviere, "Multidisciplinary approach for modelling and optimization of Road Electric Vehicles in conceptual design level" in "Electrical Systems for Aircraft, Railway and Ship Propulsion” (ESARS), 2012, 2012.6, pp. 1116-1138, 2011.

[4] Mehrdad Ehsani, Yimin Gao, Sebastien E. Gay, Ali Emadi, "Modern electric, Hybrid Electric, and Fuel Cell Vehicles-Foundamental, Theory and Design".

[5] "NASA Systems Engineering Handbook.” NASA. 1995. SP-610S.

[6] Eisner, Howard. "Essentials of Project and Systems Engineering Management." New York: Wiley; 202

[7]W. XIONG, Y. ZHANG, C. YIN, "Configuration design, energy management and experimental validation of a novel series-parallel hybrid electric transit bus" ISSN 1673-565X, China, July 20, 2008

[8] Keith B. Wipke, Matthew R. Cuddy, and Steven D. Burch , ADVISOR 2.1: "A User-Friendly Advanced Powertrain Simulation Using a Combined Backward/Forward Approach", in conference IEEE TRANSACTIONS ON VEHICULAR TECHNOLOGY, VOL. 48, NO. 6, NOVEMBER 1999.

[9] L. Horrein, A. Bouscayrol, P. Delarue, J. N. Verhille, C. Mayet . "Forward and Backward simulations of a power propulsion system", L2EP, Université Lille1, France.

[10] M.Hammadi, M.Iebba, F Camargo, O,Veneri, C. Capasso, S. Patalano, G. Copertino. "System Approach to the Pre-Design of Electric, Propulsion Systems for Road Vehicles". In conference IEEE-conferenceROME, 2015.

[11] C. Capasso, O. Veneri "Experimental analysis on the performance of lithium based batteries for road full electric and hybrid vehicles", Applied Energy, Volume 136, 31 December 2014, Pages 921-930

[12] \{SEC(2009) 1454\} \{SEC(2009) 1455\}. Proposal for a Regulation of the European Parliament and of the Council setting emission performance standards for new light commercial vehicles as part of the Community's integrated approach to reduce $\mathrm{CO}_{2}$ emission from light-duty vehicles. 